\title{
High-Velocity Gunshot Wounds to the Head: Analysis of 135 Patients
}

\author{
Abdurrahman BAKIR, Cüneyt TEMIZ*, Sukru UMUR*, \\ Varol AYDIN**, and Fuat TORUN*** \\ Department of Neurosurgery, Mevki Military Hospital, Ankara, Turkey; \\ * Department of Neurosurgery, Faculty of Medicine, Celal Bayar University, \\ Manisa, Turkey; **Department of Neurosurgery, Faculty of Medicine, \\ Adnan Menderes University, Aydin, Turkey; ${ }^{* * *}$ Department of Neurosurgery, \\ Faculty of Medicine, Ankara University, Ankara, Turkey
}

\begin{abstract}
Head injuries due to high-velocity missiles and shrapnel as a result of military conflicts have become a very important cause of death or severe neurological deficits. Military-type missiles have high velocities and transfer higher amounts of energy to neural tissue, compared to civil-type missiles. This physical phenomenon also causes greater neural tissue destruction. Shrapnel particles derive from blasts and cause less severe injury because of the irregular particle shape and low energy transmission. This study analyzed 135 patients with head trauma, 80 patients $(59 \%)$ injured by missiles and 55 patients (41\%) by shrapnel. Glasgow Coma Scale (GCS) scores at admission were 3 to 7 in 69 patients, 8 to 10 in 29 patients, and 11 to 15 in 37 patients. The most common anatomical localizations were the right frontoparietal region in 42 patients and the left frontoparietal region in 40 patients. One hundred patients $(74 \%)$ were operated on immediately and 35 patients $(26 \%)$ were treated conservatively in the intensive care unit. Ten of the 135 patients died (7.4\%), seven from missile injury and three from shrapnel injury. In this study, we found that high mortality was associated with low GCS score at admission, presence of multilobar or skull base injuries, and involvement of ventricles. Early and aggressive surgical intervention decreased the mortality.
\end{abstract}

Key words: high-velocity missile, shrapnel, head injury

\section{Introduction}

Military conflicts are constantly occurring worldwide, with the inevitable human cost of cranial penetrating missile or shrapnel injuries, which have become a very important cause of death or severe neurological deficits. The mortality, especially if the injuries were caused by military-type high-velocity missiles or particles, is high in spite of appropriate treatment, particularly compared to similar lesions in other parts of the body. These types of injuries differ from those derived from urban violence, which usually involves low-velocity missiles. Highvelocity missiles travel at speeds greater than 3000 $\mathrm{ft} / \mathrm{sec}$ and result in huge and distant tissue damage caused by temporary cavitation and shock waves. Such cavitary injury is much more extensive than

Received April 28, 2004; Accepted December 16, 2004 the track of the missile. In contrast, low-velocity missiles and shrapnel result in limited tissue damage mainly caused by tissue laceration and crushing. On the other hand, medical interventions usually cannot be performed rapidly in chaotic battlefield circumstances.

Experience in the World War I concluded that early and meticulous debridement of penetrating head wounds was the best surgical approach, decreasing the mortality to $29 \%$. In later wars, especially the World War II and Korean War, more aggressive surgery with deep debridement of necrotized brain tissue and bony fragments was shown to decrease infection and mortality. ${ }^{17,18)}$ The mortality ranges from $23 \%$ to $92 \%$ and is markedly higher at $87-100 \%$ in patients admitted with poor neurological status. . $3,8,11,13,16,19,22,23,25,29,34,35,37,39)_{\text {Many other }}$ factors have been associated with mortality including hemodynamic and respiratory status at admission, missile type, pupil diameter and reactivity, and 


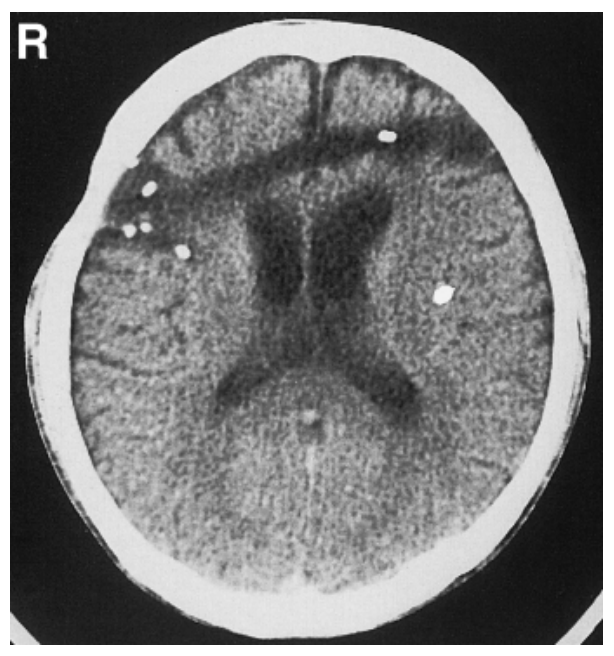

Fig. 1 Computed tomography scan showing bifrontal injury and indriven bony fragments caused by a high-velocity missile.

computed tomography (CT) findings. . $^{72,19,20,22,28,34,41)}$

Surgical intervention must be performed as soon as possible, if indicated. Operative treatment depends on some basic principles. Accurate assessment of tissue loss can only be performed in the operating room. Adequate debridement of the scalp wound and bone edges should be performed. The entire edge of the dura should be exposed and debrided. Necrotic brain tissue, hair, foreign materials, and bone fragments in the brain parenchyma are potential sources for important infections. Hemostasis of the wound and cavity is crucial to prevent rehemorrhage and herniation. The dura should be closed watertightly at the end of the operation. Scalp defects can be repaired with primary sutures or with interposition techniques. ${ }^{36)}$

The present study evaluated the surgical results of 135 patients with cranial wounds. Complete evaluation of the wound and debridement was performed if necessary. Intracerebral, subdural, or epidural hematomas were evacuated. Attentive hemostasis was performed, and dural and scalp defects were repaired.

\section{Patients and Methods}

This study evaluated 135 male patients aged from 20 to 44 years (mean 22.4 years) who suffered highvelocity missile or shrapnel wounds to the head. Patients with multiple wounds were not included. All patients were treated in the acute phase (first 3 days after injury) at Diyarbakir Military Hospital within a 2-year period. Eighty patients (59\%) were wounded by high-velocity missiles (Fig. 1) and 55

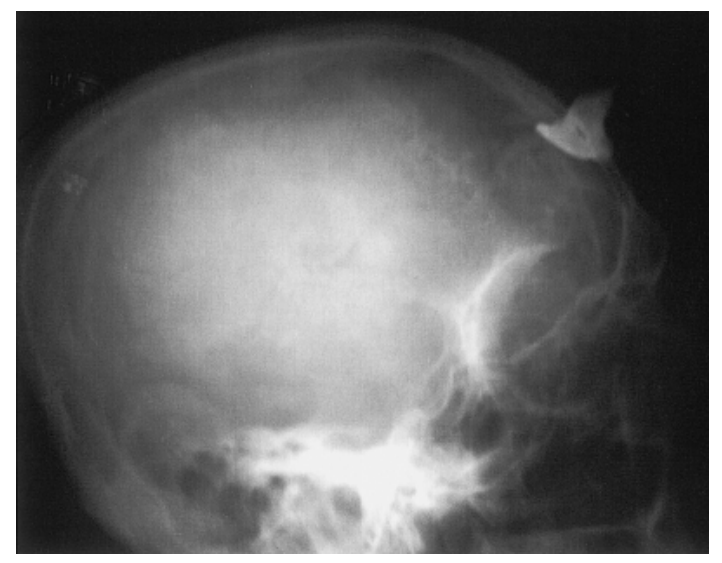

Fig. 2 Radiograph showing a shrapnel particle in the right frontal lobe which had not penetrated the skull.

patients $(41 \%)$ were injured by high-velocity shrapnel derived from explosions (Fig. 2). Military physicians began emergency treatment of all patients within the first 30 minutes including head trauma protocol and, if necessary, resuscitation procedures. All patients reached hospital within 4 hours after the trauma.

On admission to the emergency service, trauma protocol execution continued. Complete physical and neurological examinations were done rapidly. Neurological evaluation primarily depends on the Glasgow Coma Scale (GCS) parameters. Blood count and biochemical tests were also done. Biplanar cranial and cervical roentgenography and cranial CT evaluations were performed. If necessary, thoracic and lumbosacral biplanar radiography was also obtained. The decision for surgical intervention was based on the neurological examination and radiological findings. Indications for surgery were as follows: signs of elevated intracranial pressure in the presence of epidural, subdural, or intracerebral hematomas causing neurological deterioration and/or shift effect on CT; presence of a missile or shrapnel trajectory; depression type or fragmented skull fractures; presence of intracranial bony fragments and foreign materials; and extensive scalp tissue loss with ongoing hemorrhage (Figs. 3 and 4).

All surgical patients were followed and treated in the neurosurgical intensive care unit. Anti-edema therapy was given including mannitol, furosemid, and dexamethasone in the correct doses intravenously. Prophylactic antibiotic (ceftriaxone disodium) treatment was given to all patients. Famotidine (H2 receptor antagonist) injections were given intravenously to prevent damage to the stomach mucosa. 


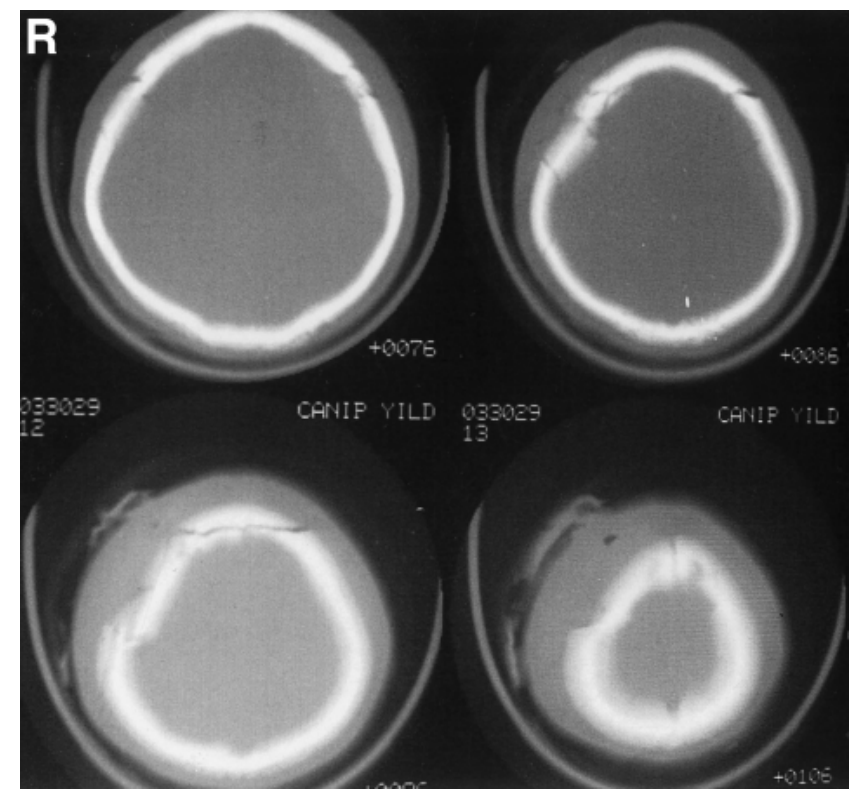

Fig. 3 Computed tomography scans showing a right frontoparietal depressed skull fracture due to a tangential high-velocity missile injury which did not penetrate the cranium.

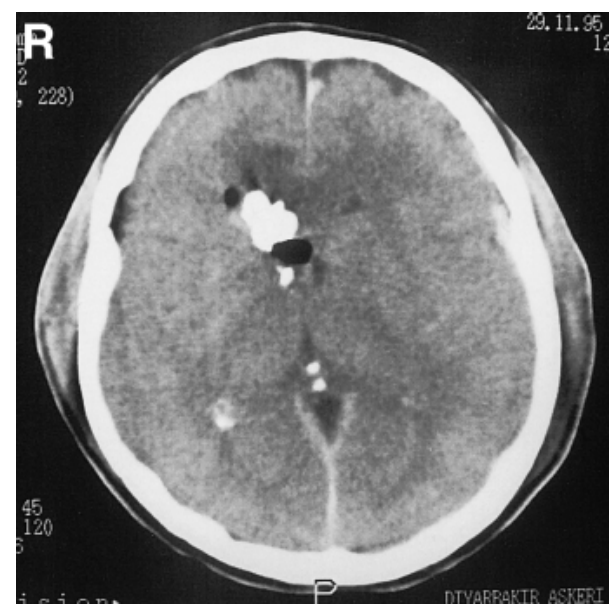

Fig. 4 Computed tomography scan showing bifrontal injuries and shrapnel particles in the brain.

GCS scores at admission, localization of injury, radiological findings, type of surgical intervention, and type of high-velocity object were recorded within the first 3 days following trauma. The correlations between the presence of variables and high mortality were investigated. These data were expressed and evaluated by the chi-square test. A p value of less than 0.05 was considered statistically significant.
Table 1 Glasgow Coma Scale (GCS) scores of the patients

\begin{tabular}{cccc}
\hline & \multicolumn{3}{c}{ GCS score } \\
\cline { 2 - 4 } & $3-7$ & $8-10$ & $11-15$ \\
\hline Missile injury $(\mathrm{n}=80)$ & $47(7)$ & $18(0)$ & $15(0)$ \\
Shrapnel injury $(\mathrm{n}=55)$ & $22(3)$ & $11(0)$ & $22(0)$ \\
\hline \multicolumn{1}{c}{ Total } & $69(10)$ & $29(0)$ & $37(0)$
\end{tabular}

Numerals in parentheses indicate number of deaths.

\section{Results}

Seventy-five of the 80 patients injured by missiles and 25 of the 55 patients injured by shrapnel underwent surgery. The other patients had nonserious injuries (only minor scalp lacerations), so only wound cleaning and closures were performed. Table 1 summarizes the GCS scores in the patients.

All patients had only cranial wounds. The most common injury location was the right frontoparietal region in 42 patients, followed by the left frontoparietal region in 40 , the right temporooccipital region in 20 , the left temporooccipital region in 15 , bifrontal regions in three, craniofacial injuries in five, skull base injuries in six, and only scalp injuries in four patients. Temporooccipital or frontoparietal describe the major topographical localizations. Multilobar injuries were present in five patients. Bifrontal injuries were evaluated separately because of their importance.

CT demonstrated the presence of indriven foreign bodies or bony fragments in 33 patients, intracerebral hematomas in 23 , edema formation in 15 , depressed skull fractures in seven, subdural hematomas in six, ventricular injuries in six, subarachnoid hemorrhages in three (Fig. 5), pneumocephalus formation in two (Fig. 6), and epidural hematoma in one patient.

The surgical interventions were excision of hematomas in 24 patients, deep debridement in 34 , excision of fragments and foreign materials in 33, ventriculostomy in three, duraplasty in 34 , and elevation of depressed skull fractures in seven patients.

Seven patients with missile injury and three patients with shrapnel injury died despite all treatment modalities (Table 1). The mortality was $8.75 \%$ for missile injury and $5.4 \%$ for shrapnel injuries. Total mortality was $7.4 \%$. Three of 135 patients had bifrontal injury and all died. Four of five patients with multilobar trajectories died. Four of six patients with ventricular injuries also died. Diffuse 


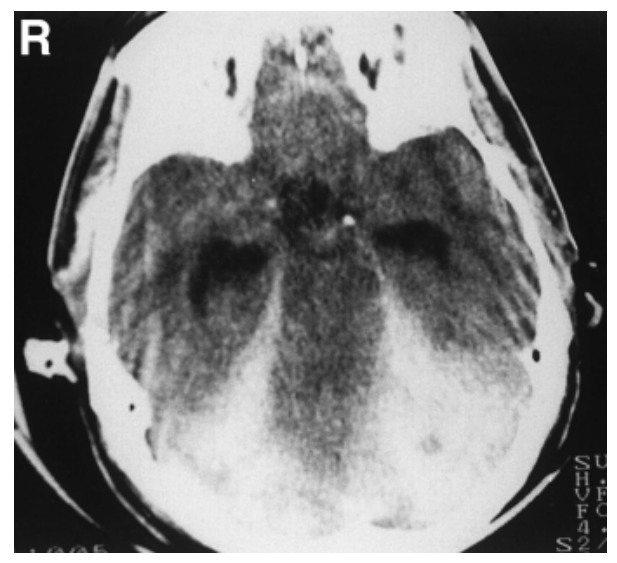

Fig. 5 Computed tomography scan showing severe subarachnoid hemorrhage following highvelocity shrapnel injury.

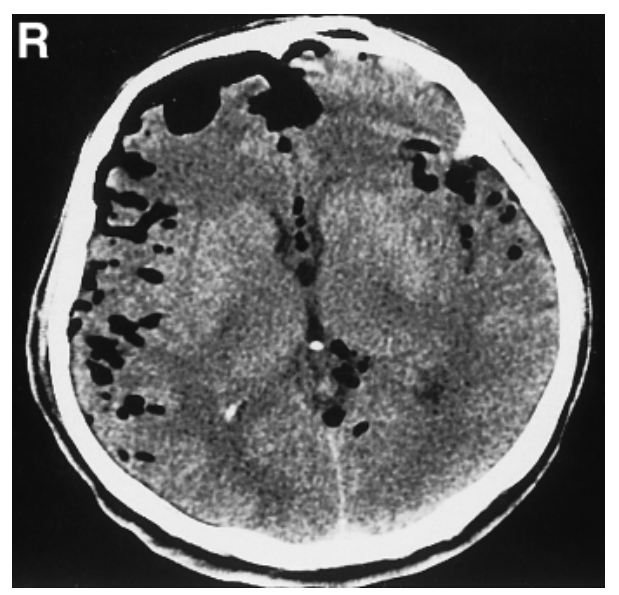

Fig. 6 Computed tomography scan showing severe pneumocephalus following a complex skull base high-velocity missile injury.

brain damage was the main cause of death, followed by herniation. Low GCS score (0 to 7 points), presence of multilobar injuries, injuries with ventricular involvement, and skull base injuries were significantly associated with high mortality ( $p<0.05$ ). Shrapnel injury had a lower mortality than missile injury $(\mathrm{p}<0.05)$.

\section{Discussion}

Mortality has been reported to increase with age, but the opposite opinion has also been expressed. ${ }^{22,24,32,39)}$ In our study, the patients tended to be younger and mortality was low. The small number of older patients included in our study did not allow any conclusion about this relationship. ${ }^{14,28,31)}$
The literature indicates some uncertainty about the relationship between the GCS scores at admission and the mortality. However, low GCS scores at admission are generally considered to be related to higher mortality. ${ }^{4,16,42)}$ In our series, this relationship was statistically significant $(\mathrm{p}<0.05)$.

The presence of multilobar injuries and involvement of ventricles were also significantly related ( $p<0.05$ ) to higher mortality in our series in accordance with other studies. ${ }^{4,12,16,20,29,37,39)}$ The high mortality in these lesions could be associated with pathophysiological mechanisms. This type of a lesion has greater potential to destroy crucial vascular structures because of the anatomical position and relatively long trajectory. The diencephalic and mesencephalic structures also tend to be destroyed. The loss of large amounts of brain tissue causes edema formation which is related with higher mortality. Localized lesions, such as contusions and intraparenchymal hematomas, are associated with surrounding edema leading to intracranial hypertension. ${ }^{1-4,39)}$ Bifrontal injury was also an important factor for mortality. The destruction of both frontal lobes can lead to more serious damage to the brain and connection fibers, and result in high mortality. In our series, we had three patients with bifrontal injury and all died in the early postoperative period despite surgical intervention.

Our study found no statistically meaningful association between the presence of pneumocephalus, epidural or subdural hematomas, or subarachnoid hemorrhage and high mortality. However, the mortality was recorded after the first 3 days postinjury, so mortality due to these factors may be higher in the long term.

Harvey Cushing was one of the first authors to suggest the necessity for aggressive surgical treatment. ${ }^{17)}$ Recently, the suggested treatment for missile or shrapnel head wounds has been divided into four groups: Large craniotomy or craniectomy and aggressive deep debridement, no surgical operation, minimal or superficial debridement, and simple debridement of the entrance gutter through a small craniotomy. ${ }^{6,10,15,33,40)}$ There is no consensus about the surgical indications or aggressiveness because of the great number of variables to be considered, such as the number and distribution of fragments, the occurrence of different types of lesions caused by different types of missiles and shrapnel particles, and the involvement of eloquent areas. Only superficial debridement of the entrance gutter and closure of the wound has been suggested.43) Urban violence tends to result in less serious injuries, mainly because of the lower missile velocity, so this treatment strategy might be valuable only 
in civil gunshot injuries. ${ }^{26)}$ In such cases, early and deep debridement of devitalized brain tissue and removal of all accessible foreign bodies and bony fragments is also advocated..$^{5,9,17,21,27,30,38)}$

The present study suggests that deep and maximal debridement of devitalized brain tissue and removal of all accessible foreign bodies and bony fragments must be performed as aggressively and early as possible to prevent the resultant edema associated with devitalized brain tissue. An indriven foreign body or large amounts of necrotic brain tissue is generally considered to be an important source for epileptic seizures and increased infection rate. ${ }^{1,9,18,19,38)}$ However, the presence of retained fragments may have no relationship with the development of either infection or seizure disorder. ${ }^{9,40)}$

The role of surgery has not been precisely defined in the treatment of patients admitted with low GCS scores. Surgery was not performed in some patients with GCS scores 3 to $5,{ }^{12,19,22,24,29)}$ because these patients have unfavorable outcome, even with surgical treatment. On the other hand, favorable outcome was achieved in some such patients, indicating deep and aggressive debridement of necrotic brain tissue to prevent the further swelling that sharply raises mortality. ${ }^{23,27)}$ We agree with this approach and performed surgical exposure and deep debridement in patients with any GCS score. We believe that our present results demonstrated that early and aggressive debridement reduces mortality. However, surgical intervention will not provide a favorable outcome in the presence of clinical signs compatible with irreversible neurological compromise.

We did not encounter any local or systemic infection, or any concomitant infection among our patients. We evaluated all our patients in the first 3 days of the post-injury period, which is too short for infection occurrence, and we gave routine combined antibiotic therapy.

The present study found that shrapnel particles produced less serious lesions and lower mortality. Due to the irregular shape of shrapnel particles, the velocity and kinetic energy decrease in a very short distance. This phenomenon results in less serious head injury if the victim is far away from the explosion that produces these types of particles.

Head injuries that occur on the battlefield have high mortality. The main cause of immediate death within 3 days of trauma is diffuse brain damage. Early surgery should stop the progressive damage and decompress the vital structures as soon as possible. The present study suggests that early and aggressive surgical intervention for debridement of necrotic brain tissue reduces brain swelling and mortality. Low GCS scores at admission, presence of multilobar injuries, injuries with ventricular involvement, and skull base injuries were associated with high mortality. Shrapnel injuries caused lower mortality, probably due to the irregular shape causing rapid decrease of kinetic energy and cranial penetration power.

\section{Acknowledgment}

We used data from the archive of the Republic of Turkey, Ministry of Defense during the preparation of this manuscript.

\section{References}

1) Aarabi B: Comparative study of bacteriological contamination between primary and secondary exploration of missile head wounds. Neurosurgery 20: 610-616, 1987

2) Aarabi B: Traumatic aneurysms of brain due to high velocity missile head wounds. Neurosurgery 22 (6 Pt 1): 1056-1063, 1988

3) Aarabi B: Causes of infections in penetrating head wounds in the Iran-Iraq War. Neurosurgery 25: 923-926, 1989

4) Aarabi B: Management of traumatic aneurysms caused by high-velocity missile head wounds. Neurosurg Clin N Am 6: 775-797, 1995

5) Aarabi B, Taghipour M, Alibaii E, Kamgarpour A: Central nervous system infections after military missile head wounds. Neurosurgery 42: 500-509, 1998

6) Aldrich EF, Eisenberg HM, Saydjari C, Foulkes MA, Jane JA, Marshall LF, Young $H$, Marmarou A: Predictors of mortality in severely head-injured patients with civilian gunshot wounds: a report from the NIH Traumatic Coma Data Bank. Surg Neurol 38: 418-423, 1992

7) Amirjamshidi A, Abbassioun K, Rahmat H: Minimal debridement or simple wound closure as the only surgical treatment in war victims with low-velocity penetrating head injuries. Indications and management protocol based upon more than 8 years followup of 99 cases from Iran-Iraq conflict. Surg Neurol 60: 105-111, 2003

8) Benzel EC, Day WT, Kesterson L, Willis BK, Kessler CW, Modling D, Hadden TA: Civilian craniocerebral gunshot wounds. Neurosurgery 29: 67-72, 1991

9) Brandt F, Roosen K, Weiler G, Grote W: [Neurosurgical management of gunshot injuries to the head]. Neurochirurgia (Stuttg) 26: 164-171, 1983 (Ger, with Eng abstract)

10) Brandvold B, Levi L, Feinsod M, George ED: Penetrating craniocerebral injuries in the Israeli involvement in the Lebanese conflict, 1982-1985. Analysis of a less aggressive surgical approach. J Neurosurg 72: 15-21, 1990

11) Brunner FX, Schwab U: Surgical management of 
trauma involving the skull base and paranasal sinuses, in Schmidek HH, Sweet WH (eds): Operative Neurosurgical Techniques, ed 3. Philadelphia, WB Saunders, 1995, pp 27-44

12) Clark WC, Muhlbauer MS, Watridge CB, Ray MW: Analysis of 76 civilian craniocerebral gunshot wounds. J Neurosurg 65: 9-14, 1986

13) Dosoglu M, Orakdogen M, Somay H, Ates O, Ziyal I: Civilian gunshot wounds to the head. Neurochirurgie 45: 201-207, 1999

14) Ewing-Cobbs L, Thompson NM, Miner ME, Fletcher JM: Gunshot wounds to the brain in children and adolescents: age and neurobehavioral development. Neurosurgery 35: 225-233, 1994

15) George ED, Dietze JB: Patient selection: determining the need for and type of surgery, in Aarabi B, Kaufman HH, Dagi F, George ED, Levy ML (eds): Missile Wounds of the Head and Neck, Neurosurgical Topics, vol 1. Park Ridge, Illinois, AANS Publication Committee, 1999, pp 130-148

16) Grahm TW, Williams FC, Harrington T, Spetzler RF: Civilian gunshot wounds to the head: a prospective study. Neurosurgery 27: 696-700, 1990

17) Hammon WM: Analysis of 2187 consecutive penetrating wounds of the brain from Vietnam. J Neurosurg 34 (2 Pt 1): 127-131, 1971

18) Hammon WM: Retained intracranial bone fragments. Analysis of 42 patients. J Neurosurg 34 (2 Pt 1): 142-144, 1971

19) Hubschmann O, Shapiro K, Baden M, Shulman K: Craniocerebral gunshot injuries in civilian practice - prognostic criteria and surgical management: experience with 82 cases. J Trauma 19: 6-12, 1979

20) Jacobs DG, Brandt CP, Piotrowski JJ, McHenry CR: Transcranial gunshot wounds: cost and consequences. Am Surg 61: 647-654, 1995

21) Kaufman HH, Loyola WP, Makela ME, Frankowski RF, Wagner KA, Bernstein DP, Gildenberg PL: Civilian gunshot wounds: the limits of salvageability. Acta Neurochir (Wien) 67: 115-125, 1983

22) Kaufman $\mathrm{HH}$, Makela ME, Lee KF, Haid RW, Gildenberg PL: Gunshot wounds to the head: a perspective. Neurosurgery 18: 689-695, 1986

23) Kennedy F, Gonzalez P, Dang C, Fleming A, SterlingScott R: The Glasgow Coma Scale and prognosis in gunshot wounds to the brain. J Trauma 35: 75-77, 1993

24) Levy ML, Masri LS, Lavine S, Apuzzo ML: Outcome prediction after penetrating craniocerebral injury in a civilian population: aggressive surgical management in patients with admission Glasgow Coma Scale scores of 3, 4, or 5. Neurosurgery 35: 77-85, 1994

25) Levy ML, Masri LS, Levy KM, Johnson FL, MartinThomson E, Couldwell NT, McComb JG, Weiss MH, Apuzzo ML: Penetrating craniocerebral injury resultant from gunshot wounds: gang-related injury in children and adolescents. Neurosurgery 33: 1018-1025, 1993

26) Martins RS, Siqueira MG, Santos MT, Zanon-
Collange N, Moraes OJ: Prognostic factors and treatment of penetrating gunshot wounds to the head. Surg Neurol 60: 98-104, 2003

27) Meirowsky AM: Secondary removal of retained bone fragments in missile wounds of the brain. J Neurosurg 57: 617-621, 1982

28) Miner ME, Ewing-Cobbs L, Kopaniky DR, Cabrera J, Kaufmann P: The results of treatment of gunshot wounds to the brain in children. Neurosurgery 26: 20-25, 1990

29) Nagib MG, Rockswold GL, Sherman RS, Lagaard MW: Civilian gunshot wounds to the brain: prognosis and management. Neurosurgery 18: 533-537, 1986

30) Nathoo N, Chite SH, Edwards PJ, van Dellen JR: Civilian infratentorial gunshot injuries: outcome analysis of 26 patients. Surg Neurol 58: 225-233, 2002

31) Ordog GJ, Prakash A, Wasserberger J, Balasubramaniam S: Pediatric gunshot wounds. J Trauma 27: 1272-1278, 1987

32) Paret G, Dekel B, Yellin A, Hadani M, Weissman D, Vardi A, Hoffman C, Knoller N, Ohad G, Barzilay Z: Pediatric craniocerebral wounds from plastic bullets: prognostic implications, course, and outcome. J Trauma 41: 859-863, 1996

33) Rish BU, Dillon JD, Caveness WF, Mohr JP, Kistler JP, Weiss GH: Evolution of craniotomy as a debridement technique for penetrating craniocerebral injuries. J Neurosurg 53: 772-775, 1980

34) Rosenfeld JV: Gunshot injury to the head and spine. J Clin Neurosci 9: 9-16, 2002

35) Saba MI: Surgical management of gunshot wounds of the head, in Schmidek HH, Sweet WH (eds): Operative Neurosurgical Techniques. Philadelphia, WB Saunders, 1988, pp 37-49

36) Saba MI: Surgical management of missile injuries of the head, in Schmidek HH, Sweet WH (eds): Operative Neurosurgical Techniques, ed 3. Philadelphia, WB Saunders, 1995, pp 89-104

37) Semple PL, Domingo Z: Craniocerebral gunshot injuries in South Africa - a suggested management strategy. S Afr Med J 91: 141-145, 2001

38) Sherman WD, Apuzzo MLJ, Heiden JS, Petersons VT, Weiss MH: Gunshot wounds to the brain: a civilian experience. West J Med 132: 99-105, 1980

39) Shoung HM, Sichez JP, Pertuiset B: The early prognosis of craniocerebral gunshot wounds in civilian practice as an aid to the choice of treatment. A series of 56 cases studied by the computerized tomography. Acta Neurochir (Wien) 74: 27-30, 1985

40) Splavski B, Vrankovic D, Saric G, Saftic R, Maksimovic Z, Bajek G, Ivekovic V: Early surgery and other indicators influencing the outcome of war missile skull base injuries. Surg Neurol 50: 194-199, 1998

41) Stone JL, Lichtor T, Fitzgerald LF: Gunshot wounds to the head in civilian practice. Neurosurgery 37: 1104-1112, 1995

42) Suddaby L, Weir B, Forsyth C: The management of. 22 caliber gunshot wounds of the brain: a review of 49 cases. Can J Neurol Sci 14: 268-272, 1987 
43) Taha JM, Saba MI, Brown JA: Missile injuries to the brain treated by simple wound closure: results of a protocol during the Lebanese conflict. Neurosurgery 29: 380-384, 1991

Address reprint requests to: A. Bakir, M.D., Mevki Military Hospital, Ankara, Turkey.

e-mail: abdbak@hotmail.com

\section{Commentary}

This is an important report, as it is a current account on injuries inflicted by modern high velocity bullets. As the authors report on 135 patients treated within 2 years, they have gathered considerable experience in a short time. Comparing high velocity missiles with shrapnel lesions resulted in a lower mortality for shrapnel injuries. Bifrontal lesions and multilobar injuries and involvement of ventricles were all associated with a higher mortality. With the authors' regime of early debridement with adequate removal of dead tissue and bone fragments, no case of local or systemic infection was observed and pneumocephalus was not associated with increased mortality. Obviously these results support the early surgery the authors advocate and should be considered when gunshot wounds need to be treated.

Raimund FIRSCHING, M.D., L.R.C.P., M.R.C.S. Klinik für Neurochirurgie Otto-von-Guericke-Universität Magdeburg, Germany 